\title{
Cognitivism and Ultrasound Skills in Emergency Medicine Training: From Theory to Practice
}

\author{
Taiwo Akhigbe ${ }^{1^{*}}$ \\ 'Department of Emergency Medicine, Altnagelvin Hospital, Northern Ireland, UK
}

Corresponding Author: Taiwo Akhigbe, MBBS, MCh, MSc, PgD, FRSPH, Department of Emergency Medicine, Altnagelvin Hospital, Northern Ireland, UK. Tel: +44-7459712427, Email: akhigbetaiwo@yahoo.com

Received March 25, 2018; Accepted May 19, 2018; Online Published June 25, 2018

\begin{abstract}
Learning theories are not just an academic concept, but are essential in developing sound principles and a framework of result-oriented learning. This gives the foundation of proficient teaching methods in the communication of significant learning information to meet the needs of both the trainee and the trainer as well as the curriculum. In emergency medicine training, ultrasonography requires a combination of motor, visual and cognitive skills. Simulation-based ultrasound training is essential for technicians to progress from learners to expert. Cognitivism, a learning theory, is relevant to the development of ultrasound skills through the application of its key principles in emergency medicine training.

Keywords: Cognitive Science, Ultrasound Imaging, Emergency Medicine

Citation: Akhigbe T. Cognitivism and ultrasound skills in emergency medicine training: from theory to practice. Int J Med Rev. 2018;5(2):47-49. doi:10.29252/IJMR-050201.
\end{abstract}

\section{Introduction}

Quality and competency-based training of the next generation of emergency medicine physicians involves not just the proper interpretation of learning theory, but its adequate application in practice. Learning theories are not just academic concepts; they are essential for the development of sound principles and a framework of result-oriented learning. Furthermore, they provide the foundation of proficient teaching methods in the communication of significant learning information to meet the needs of both the trainee and the curriculum. ${ }^{1}$ Point-ofcare ultrasound (POCUS) as a useful tool in the diagnosis and treatment procedures for both stable and unstable patients in the emergency department (ED). Ultrasonography is a fundamental skill to develop, and practicing emergency medicine without it is almost unethical. The America Council of EM Residency Directors (CORD) released recommendations on the assessment of ultrasound skills and image interpretation. ${ }^{2}$ POCUS is fast becoming a strategic part of emergency medicine training; hence, its appropriate and proficient use is an essential standard practice. Understanding cognitivism can give significant depth to teaching, and the pitfalls that occur from its misapplication can be avoided. The present article offers viewpoints on translating cognitive learning theory into practice in learning POCUS in EDs.

\section{Cognitive Theory and Emergency Ultrasound Skill Acquisition \\ Cognitivism focuses on the thought processes, ideas, and}

concepts associated with learning. The learner employs cognitive tools including insight, information processing, perception, and memory in facilitating learning. ${ }^{3}$ Ultrasound skills consist of motor skills, hand-eye coordination, and visual-cognitive skills useful in image search and interpretation. Fitts and Posner ${ }^{4}$ proposed a motor skills development model comprising cognitive, associative, and autonomous stages. The cognitive stage involves the conscious planning of hand-eye movement and coordination; with continued and consistent practice, the learner progresses into the associative stage with better, faster, and well-grounded movements. After further practice, the autonomous stage is achieved with consistent, efficient, and faster movements and negligible cognitive input.,

Visual-cognitive skills are essential for an emergency medicine trainee to translate two-dimensional images into three-dimensional representations based on the anatomy of the organs in question. Visual and cognitive skills are indispensable in the search and interpretation of images. ${ }^{6}$ A visual search is made up of two components: prior global impression and focal search. ${ }^{7}$ The search is characterized by the key features of shape, color, and symmetry of relevant features being compared with previous experiences and evaluated. ${ }^{8}$ Longer viewing times are exhibited by a novice. ${ }^{9}$ It is taught that organized past experiences in a physician's cognitive schema can lead to increasing levels of expertise in imaging and interpretation. ${ }^{10,11}$ Larger chunks of information are aggregated into an elaborate memory

Copyright (C) 2018 The Author(s). This is an open-access article distributed under the terms of the Creative Commons Attribution License (http:// creativecommons.org/licenses/by/4.0), which permits unrestricted use, distribution, and reproduction in any medium, provided the original work is properly cited. 
structure by experienced physicians over time. ${ }^{10}$ This use of chunk information allows experienced physicians to arrive at pattern-recognition diagnoses by relying on little pieces of information. ${ }^{11}$

Memory and the handling of information are recognized as the pillars of cognitivism. Working memory is useful in effective ultrasonography, but it can be overwhelming. It has a limited capacity and can hold only five to nine chunks of information. ${ }^{12}$ This is supported by cognitive load theory (CLT), which is a significant aspect of cognitivism and is very relevant in the acquisition of ultrasound skills. CLT is composed of three groups influencing working memory: intrinsic load (associated with performing tasks), extraneous load (associated with non-essential parts of a task), and germane load (associated with benefits to the act of learning). ${ }^{13,14}$ Working memory load is based majorly on the intrinsic load, but when this does not produce the necessary learning, it is the extraneous load which arises from nonessential instruction that cannot contribute to improving the specific knowledge or task performance. ${ }^{15}$ As the learning of ultrasound skills progresses, expertise increases and the intrinsic load is reduced.

Learning a psychomotor skill like ultrasound technology involves five components: attention, perception, concept formation, memory, and learning. ${ }^{16}$ The interplay of these components is caused by visual, auditory, haptic, and other stimuli. The process of attention to perception and conceptualization allows information to be stored in the long-term memory, which is subject to significant recall and execution of task again, if required. ${ }^{16}$ Furthermore, with extensive training, hand-eye coordination will lead to a decrease in the cognitive load of the technical aspects of ultrasound skills.

\section{From Theory to Practice: Applying the Principle}

Ultrasonography has become a significant part of emergency medicine, and it is an important skill which can positively affect patient outcome. Current training in emergency ultrasonography involves the apprentice model, in which the learner observes the senior emergency physician (consultant or registrar) and receives supervision and guidance during the procedure. Further learning and practice including social interaction leading to community of practice as proficient and independent learners. ${ }^{17}$ Frequent interaction with senior clinicians is common place in workplacebased learning; however, research has shown that frequent supervision in the workplace is perceived by trainees as a threat to their credibility and should be avoided. ${ }^{18}$ The Clinical Apprenticeship teaching model is a current method of ultrasonography training in EDs, with which a learner or junior trainee observes the senior emergency medicine clinicians and receives ongoing supervision during the training period, including personal self-directed workplace learning and practice, termed the concept of legitimate peripheral participation. ${ }^{19}$ Point-of-care ultrasonography in emergency medicine includes echocardiography during cardiac arrest, evaluation of deep vein thrombosis (DVT), thrombosis, and abdominal and trauma ultrasonography. Learning this skill is greatly influenced by cognitive theory. Ultrasound training is time- and resource-dependent, requiring multiple years of training before supervision is no longer needed. According to Ericsson et $\mathrm{al}^{20}$ the combination of repeated practice or deliberate practice and expert supervision is attained through a deliberate effort to improve. An extended training period can lead to prolonged retention of knowledge producing better outcomes.

This principle can also be applied in simulation-based ultrasound training. The use of virtual reality simulators has become a fundamental component of technical skill training and development. The effectiveness of simulation-based medical education has been demonstrated in several reviews and has been found to produce a better learning outcome. ${ }^{21}$

\section{Conclusions}

Cognitivism is a learning theory that is applicable to the development of ultrasound skills in emergency medicine training attained by applying its key principles in teaching and learning. The implementation of the CLT strategy helps to manage the intrinsic load, reduce the extraneous load, and optimize the germane load in ultrasound skills. This approach in teaching and learning ultrasound skills using five cognitive model will have positive implications for the promotion of learning this skill.

\section{Conflict of Interest Disclosures}

The author declares that there is no conflict of interest.

\section{References}

1. Illeris K. Contemporary theories of learning: Learning theorists... in their own words. Taylor \& Francis; 2018. doi:10.4324/9781315147277.

2. Akhtar S, Theodoro D, Gaspari R, et al. Resident training in emergency ultrasound: consensus recommendations from the 2008 Council of Emergency Medicine Residency Directors Conference. Acad Emerg Med. 2009;16 Suppl 2:S32-36. doi:10.1111/j.15532712.2009.00589.x.

3. Badyal DK, Singh T. Learning Theories: The Basics to Learn in Medical Education. Int J Appl Basic Med Res. 2017;7(Suppl 1):S1S3. doi:10.4103/ijabmr.IJABMR_385_17.

4. Fitts PM, Posner MI. Human performance. 1st ed. Belmont, Calif: Brooks/Cole Pub. Co; 1967.

5. Wulf G. Attention and Motor Skill Learning. 1st ed. Champaign, IL, US: Human Kinetics; 2007.

6. Lesgold A, Rubinson H, Feltovitch P, Glaser R, Klopfer D, Wang $\mathrm{Y}$. Expertise in a complex skill: Diagnosing x-ray pictures. In: Chi MTH, Glaser R, Farr MJ, eds. The nature of expertise. Hillsdale, NJ, US: Lawrence Erlbaum Associates, Inc; 1988:311-342.

7. Krupinski EA. The role of perception in imaging: past and future. Semin Nucl Med. 2011;41(6):392-400. doi:10.1053/j. semnuclmed.2011.05.002

8. Nodine CF, Kundel HL, Mello-Thoms C, et al. How experience and training influence mammography expertise. Acad Radiol. 1999;6(10):575-585. doi:10.1016/S1076-6332(99)80252-9.

9. Nodine CF, Kundel HL, Lauver SC, Toto LC. Nature of expertise in searching mammograms for breast masses. Acad Radiol. 1996;3(12):1000-1006. doi:10.1016/S1076-6332(96)80032-8.

10. Schmidt HG, Norman GR, Boshuizen HP. A cognitive perspective on medical expertise: theory and implication. Acad Med. 1990;65(10):611-621. doi:10.1097/00001888-19901000000001.

11. Norman GR, Coblentz CL, Brooks LR, Babcook CJ. Expertise in 
visual diagnosis: a review of the literature. Acad Med. 1992;67(10 Suppl):S78-S83. doi:10.1097/00001888-199210000-00045.

12. Miller GA. The magical number seven, plus or minus two: some limits on our capacity for processing information. 1956. Psychol Rev. 1994;101(2):343-352.

13. Sweller J, Ayres P, Kalyuga S. Cognitive load theory. New York: Springer; 2011. doi:10.1007/978-1-4419-8126-4.

14. Sweller J. Cognitive load during problem solving: Effects on learning. Cogn Sci. 1988;12(2):257-285. doi:10.1016/03640213(88)90023-7.

15. Leppink J, Paas F, van Gog T, van der Vleuten CPM, van Merrienboer JJG. Effects of pairs of problems and examples on task performance and different types of cognitive load. Learn Instr. 2014;30:32-42. doi:10.1016/j.learninstruc.2013.12.001.

16. Ashwini R. Cognition and motor skills. In: Henderson A, Pehoski C, eds. Hand Functions in the child: Foundation for Remediation. Missouri: Mosby/Elsevier; 2006.
17. Wenger E. Communities of practice: Learning, meaning, and identity. Cambridge: Cambridge University Press; 1998. doi:10.1017/CBO9780511803932.

18. Kennedy TJ, Regehr G, Baker GR, Lingard L. Preserving professional credibility: grounded theory study of medical trainees' requests for clinical support. BMJ. 2009;338:b128. doi:10.1136/bmj.b128.

19. Lave J, Wenger E. Situated Learning: Legitimate Peripheral Participation. 1st ed. Cambridge: Cambridge University Press; 1991. doi:10.1017/CBO9780511815355.

20. Ericsson KA, Krampe RT, Tesch-Romer C. The role of deliberate practice in the acquisition of expert performance. Psychol Rev. 1993;100(3):363-406. doi:10.1037//0033-295X.100.3.363.

21. Teteris E, Fraser K, Wright B, McLaughlin K. Does training learners on simulators benefit real patients? Adv Health Sci Educ Theory Pract. 2012;17(1):137-144. doi:10.1007/s10459-011-9304-5. 